\title{
Del líquido vital: entre la escasez y el valor de uso en la reproducción social campesina. Cruz del Eje, Córdoba (Argentina)
}

\author{
About water access: scarcity and use value in peasant social reproduction. Cruz del Eje, Córdoba (Argentina) \\ Magali Luciana Paz \\ Centro de Investigaciones en Cultura y Sociedad, \\ CONICET. Universidad Nacional de Córdoba, Argentina \\ magaliartano@gmail.com
}

Karina Verónica Fleitas

Facultad de Filosofia y Humanidades, Universidad

Nacional de Córdoba, Argentina

karyfleitas19@hotmail.com

\begin{abstract}
Resumen:
En este artículo presentamos un análisis sobre el acceso al agua en unidades campesinas situadas en la margen izquierda del dique Cruz del Eje. Primero, el trabajo indaga sobre el sustento ideológico y económico de la construcción de dicho embalse en la década de 1940. Luego, se determina el impacto que comportan las disputas por el acceso al agua en la reproducción de estas comunidades rurales. Así, desde un abordaje histórico-antropológico, y tomando en cuenta diferentes indicadores, llegamos a la conclusión de que la construcción del dique generó una afectación particular sobre la población local, y que, en consecuencia, existen diferencias sustanciales entre las zonas con acceso al agua y aquellas establecidas como de riego eventual.
\end{abstract}

Palabras Clave: Agua, Unidad doméstica campesina, Infraestructura hidroeléctrica, Conflicto social, Recursos naturales.

\section{Abstract:}

In this article, we present an analysis of access to water in peasant units located on the left side of the Cruz del Eje dam. First, the work investigates the ideological and economic sustenance of the construction of this reservoir in the 1940s. It then determines the impact that disputes over access to water in the region have on the reproduction of these rural communities. Thus, from an historical-anthropological approach, and taking account different indicators, we come to the conclusion of the dam generated a particular effect on the local population and that, consequently, there are substantial differences between areas with access to water and those established as provisional irrigation.

KeYwORDs: Water, Peasant households, Hydroelectric infrastructure, Social conflict, Natural resources.

\section{INTRODUCCIÓN}

El artículo se concentra en el análisis de las particularidades históricas y culturales del sistema de regadío del dique Cruz del Eje, en el contexto de expansión de la frontera agroganadera en la región, y atiende a las problemáticas de las unidades domésticas en sus conflictos por el acceso a los recursos vitales. El texto intenta explicar por qué las comunidades rurales ubicadas en los espacios denominados "fuera de zona" de riego, a la margen izquierda del dique más extenso de Latinoamérica, poseen dificultades estructurales para acceder al agua. En este sentido, sostenemos que a partir de la construcción del dique Cruz del Eje (década de 1940) existe una reconfiguración socioterritorial que conforma un marco de desigualdad en la región: las familias campesinas ubicadas en los espacios de estudio no participan directamente en el Comité de Cuenca ni en el Consorcio de Regantes, lo cual obstruye las demandas de sus propios intereses. Bajo tales condiciones, caracterizamos a los espacios fuera de zona como sitios marginales del ámbito rural cruzdelejeño, donde 
habita el mayor porcentaje de población, con predominio de economía campesina del departamento, y cuyos problemas principales de producción y reproducción tienen su causa en el déficit hídrico, sumado a una problemática mayor, la propiedad de la tierra, dado que la mayoría de las familias campesinas son poseedoras y no tienen títulos saneados.

\section{SOBRE EL ENFOQUE TEÓRICO-METODOLÓGICO}

Durante las últimas décadas, las posibilidades de que las familias campesinas logren un nivel de vida razonable en el medio rural de nuestro continente se han vuelto casi inexistentes (Barkin, 2001; Dávila Ladrón de Guevara, 2011). Es decir, nos encontramos ante uno de los momentos más conflictivos de los sistemas productivos agrarios en toda Latinoamérica (pérdida de la autonomía alimentaria, agotamiento de los recursos ambientales debido a las características de explotación y producción cortoplacista, entre otras). En relación al recurso hídrico, se observa en América Latina un proceso constante de apropiación y monopolización por parte de sectores económicos poderosos del mismo, caracterizado ya como un "bien económico". Otra cuestión que se advierte es la naturalización del accionar de estos sectores poderosos facilitada, muchas veces, por el amparo de instrumentales estatales, en contraposición a sectores rurales vulnerables y afectados por la escasez o la contaminación producida sobre el líquido vital (Escobar, 2007; Carruthers, 2008).

Para Jorge Veraza (2007), el agua es un bien común; tiene valor de uso y forma parte de la riqueza nacional de un Estado. El conflicto se genera cuando dicho recurso, esencial para la vida en su totalidad, se mercantiliza y adquiere rasgos de bien como valor de cambio: "El agua es un bien de uso que es manipulado por el ser humano de manera colectiva o individual, pero también es patrimonio de la humanidad porque es premisa constitutiva y generativa de la vida" (Veraza, 2007, p. 19). Existe una diferencia inminente entre el valor impuesto a partir del precio sobre el agua y las subsiguientes obras hidráulicas que requiere un sistema de riego modernizado, las cuales son llevadas adelante por los Estados para la potabilización, la canalización, murallas de contención, etcétera. De esta forma, el autor plantea que el agua no es mercancía ni puede serlo porque no contiene en sí mismo valor, solo se le puede agregar, y es ello lo que se mercantiliza a través de lo que denomina Procesos Hidroútiles (PHU), entendidos como "todos aquellos procedimientos laborales humanos que permiten volverla útil" (Veraza, 2007, p. 20). Es decir, estos procesos que requieren de trabajo humano son los susceptibles de convertirse en mercancía, empero, alude el autor, incluso los PHU que contienen valor no pueden ser lucrativos, ya que juegan con las condiciones de existencia de la vida de todas las especies.

Ahora bien, adoptar esta perspectiva no implica reconocer el poder de los bienes y sentidos socioculturales hegemónicos como poder omnímodo. Por el contrario, esos bienes y sentidos siempre pueden volverse objeto de demanda, de apropiación o de resistencia (Roseberry, 2007), y movilizar a los colectivos sociales, aunque con sentidos políticos imposibles de definir apriorísticamente.

La reseña presentada permite abrir nuevos interrogantes en relación al impacto del proceso de mercantilización, uso y distribución del agua en la región de estudio. En primer lugar, y referido la implementación del sistema de riego del dique Cruz del Eje, ¿̨por qué las familias campesinas se encuentran aisladas del sistema de distribución de agua? Como se verá más adelante, la construcción del dique tenía como objetivo principal ampliar las zonas de regadío, elevar la población y el desarrollo económico de una región semiárida como es el noroeste de Córdoba. En segundo lugar, en el departamento Cruz del Eje durante las últimas décadas avanzó el proceso de mercantilización de tierras de la mano de productores-empresarios extralocales, razón por la cual emergieron conflictos por el uso y apropiación de los recursos en el territorio. ¿Cuáles son las estrategias socioeconómicas de los grupos domésticos para reconstruir su subsistencia a diario en el marco de dichas transformaciones del agronegocio regional?

Antes de responder a estos interrogantes se deben determinar las causas que dieron origen al dique Cruz del Eje, pero dentro de la noción de que un sistema de riego no implica solo un proyecto económico o 
una obra física, sino también, y sobre todo, una construcción social (Bustos y Yáñez, 2004; Raucsh, 2016). Luego hay que evaluar los mecanismos que favorecieron/favorecen procesos de expulsión de las poblaciones actualmente asentadas en la margen izquierda del sistema de riego del mencionado embalse. Es decir, qué magnitud alcanzan estos procesos en la actualidad (año 2016). Así se podrá apreciar, consecuentemente, el rol que juegan los sectores privados y/o aquellos beneficiados por intereses compartidos con el Estado provincial.

En términos metodológicos adscribimos a la corriente de la antropología histórica consistente en la realización de minuciosas etnografías, que permiten analizar cómo determinados procesos se manifiestan en ámbitos concretos y particulares de forma que se puedan determinar las variables diferenciales que concurren en cada contexto social (Rockwell, 2009). Integrar la dimensión histórica al trabajo etnográfico nos requirió recolectar información muy fragmentaria y dispersa en diversas fuentes documentales y bibliográficas que serán oportunamente citadas. El trabajo de campo se llevó a cabo en el departamento Cruz del Eje, Córdoba. Se efectuaron estadías de aproximadamente 15 días en las localidades bajo análisis entre enero de 2012 y abril de 2016. En el caso de los trabajos en los meses de verano, las estadías tuvieron una duración de 20 días, aproximadamente. La consecución del trabajo de campo se efectuó a partir de las técnicas habituales en Antropología Social, a saber: observación con participación, entrevistas abiertas, semiestructuradas y en profundidad, e historias de vida. En este sentido, utilizamos un tipo de diseño de investigación cualitativa que se basa en un muestreo intencional y por bola de nieve, donde los sujetos entrevistados conducen a otros, y así sucesivamente. En investigaciones cualitativas como éstas no se pretende extrapolar los resultados a toda la población, sino más bien comprender en toda su riqueza la perspectiva de los sujetos; lo importante es captar la profundidad, más que la extensión (Vasilachis de Gialdino, 2007). Las entrevistas realizadas son propiamente antropológicas, es decir, no directivas: "este tipo de entrevista cabe plenamente en el marco interpretativo de la observación participante, pues su valor no reside en su carácter referencial sino performativo" (Guber, 2012, p. 69), y fueron concretadas in situ. El criterio de relevancia consistió en seleccionar a los entrevistados en la medida que permitieran ampliar el rango de heterogeneidad del universo para que emergieran nuevas categorías de análisis, las cuales orientaron, a su vez, la búsqueda de nuevos casos (el uso del software atlas/ti agilizó el trabajo de sistematización, análisis e interpretación de datos). Forman parte de la muestra las unidades domésticas ubicadas en la margen izquierda del sistema de riego del dique Cruz del Eje, donde se identificaron grupos dentro de zona de riego (comunas de Media Naranja, Alto de los Quebrachos, y paraje Palo Parado), y grupos fuera de zona de riego (comuna de Guanaco Muerto, y parajes Santo Domingo, San Antonio, El Abra), que poseen dificultades estructurales para obtener agua ${ }^{1}$.

Es conveniente aclarar a qué nos referimos cuando hablamos de las Unidades Domésticas ${ }^{2}$. Se trata de unidades de análisis trabajadas en estudios económicos en general, y desde la antropología económica en particular (Chayanov, 1974; Meillassoux, 1977; Wilk y McC. Netting, 1984; Harris, 1986). A partir de dichas referencias podemos establecer cuáles son las características de las U.D. campesinas en el capitalismo periférico. Se trata de explotaciones en pequeña escala, diversificadas, con un precario nivel tecnológico, uso preponderante del trabajo familiar y que cuentan con la posesión de los medios de producción. Los componentes más importantes del ingreso total derivan de la producción agropastoril. Estos grupos domésticos constituyen "un sistema de relaciones sociales que basado en el principio de residencia común regula y garantiza el proceso productivo" (Archetti y Stölen, 1975, p. 51). En ese sentido, utilizamos el término campesino para agrupar al conjunto de pequeños productores, o de pastores y agricultores, en distintas zonas del noroeste de la provincia de Córdoba, tomando en consideración una característica básica y común que es la utilización de mano de obra familiar. Asimismo, es factible afirmar que estos pequeños productores, bajo una amplia gama de figuras jurídicas (propiedad, arrendamiento, ocupación precaria, asentamiento ilegal, entre otros) disponen de acceso al recurso tierra y controlan el proceso productivo desde una lógica de subsistencia familiar, complementándolo en ocasiones con el trabajado rural intermitente en la grandes unidades productivas de la región, o el cobro de subsidios y/o pensiones estatales. 
Una de nuestras hipótesis de trabajo refiere a que en el noroeste cordobés en general, y en el departamento de Cruz del Eje en particular, se verifica un progreso del capital agrario a expensas de las economías domésticas, que implica un avance de la frontera agrícola-ganadera sobre zonas antaño consideradas de poco rinde o marginales en cuanto a su valor productivo. Dicho avance es llevado adelante por empresas agropecuarias con fuerte inversión de capital, que hacen uso de una explotación intensiva de los recursos naturales existentes en el territorio (desmonte indiscriminado, explotación extractiva y degradante, uso de agroquímicos, monopolización del recurso hídrico, etc.), y esta lógica de explotación se opone a la lógica en el manejo de los recursos que históricamente ha realizado -y realiza- el sector campesino. Sin embargo, en regiones como el noroeste cordobés - "donde la composición orgánica del capital en la rama de la producción es baja, y por tanto, coexisten en su estructura agrícola diferentes clases, siendo relativamente altos los grados de participación de la producción familiar" (Barri, 2013, p. 224)-, tomamos como idea central que el capital no controla directamente el proceso de trabajo doméstico.

En efecto, la subsunción del sector doméstico al capital en la región constituye una "subsunción indirecta" ${ }^{3}$, más allá de que estacionalmente el sector doméstico vende su fuerza de trabajo -subsunción directa-. Para explicar de manera más completa el concepto de subsunción mediada o indirecta del trabajo al capital las referencias teóricas ineludibles son Bartra (1982), Gutiérrez Pérez y Trápaga Delfín (1986), y Gordillo (1992; 2006). Este último autor define la palabra mediación no como un mero elemento intermedio, sino más bien un factor que configura la relación entre dos factores. Las mediaciones son intrínsecas al proceso de subordinación e influyen como sectores capitalistas afectando a las prácticas de los grupos domésticos. (Gordillo, 2006, p. 104). He aquí el punto más importante que nos interesa del concepto de subsunción mediada del trabajo al capital: el carácter indirecto y, por ende, mediatizado -con características propias del territorio local- de estos condicionamientos es el que le permite a los grupos domésticos crear ámbitos de relativa autonomía y generar estrategias través del sentido práctico (sin cálculos racionales la mayoría de las veces) para garantizar su subsistencia a pesar de la explotación.

\section{Las UnidADEs Domésticas CRUZDEleJeñas y EL ACCESo a los RECURSOS}

En su extremo noroeste, Córdoba comparte con las provincias vecinas de La Rioja, Catamarca y Santiago del Estero, las denominadas Salinas Grandes y Salinas de Ambargasta, que forman parte de la zona más árida y calurosa de la provincia. En ella se encuentra el complejo hoy conocido como bosque chaqueño (también denominado "monte"), cuyas especies típicas son el molle de beber, el coco y el quebracho serrano o cordobés, tala, mistol, chañar, algarrobo y espinillo. Durante las ltimas tres décadas del siglo XX, el factor de cambio en la cobertura de la región estuvo dominado por la "conversión de bosques en tierras agrícolas" (Cabido y Zak, 2010, p. 7). Los departamentos de Ischilín, Tulumba, Río Seco, Cruz del Eje y Río Primero han sido los de mayor superficie deforestada. "De acuerdo con el Mapa Forestal de la Provincia de Córdoba, la superficie ocupada por monte nativo se encuentra fragmentada y forma islas de bosque que superan las 10.000 ha en contados casos" (Pegoraro et al., 2013, p. 5). Justamente, la que se encuentra al borde de la pérdida total de sus bosques es la subregión semiárida del límite sur, denominada rida de Traslasierra de producción Ganadera Extensiva del Noroeste de la Provincia, que está definida como una región cuya actividad principal es la ganadería, tanto de bovinos como de caprinos, donde la cría se realiza de manera extensiva, a partir de las pasturas naturales y los recursos forrajeros del monte. En ella la agricultura es secundaria, y el cultivo predominante es el maíz. El clima es semiárido y la provisión natural de agua es escasa; en la mayoría de los casos con intervención antropogenética (Ghida Daza y Sánchez, 2009).

A su vez, la literatura existente coincide en señalar que la región del noroeste se ratifica como el área con mayor cantidad y diversidad de productores familiares, y como el territorio donde se concentra el mayor número de situaciones conflictivas de tenencia de la tierra, los menores niveles de capitalización en el sistema agrario, un amplio predominio del trabajo familiar, y las condiciones más comprometidas de reproducción 
social de los sistemas productivos: "Esta área presenta condiciones de vulnerabilidad y riesgos generalizados para mantenerse en la estructura productiva” (Bergamín, 2007, p. 58). Los datos referentes a la estructura agraria (con base en el Censo Nacional Agropecuario 2002-2008) avalan las afirmaciones antes mencionadas: en la región existían 2.274 Explotaciones Agropecuarias (EAPs), que ocupaban una superficie de 1.195.966 ha y explotaban una superficie media de 529,5 ha. La mayoría de las explotaciones se encontraban en el estrato de menos de 100 ha (58 \%), con una superficie media de 29,5 ha. La comparación del CNA 2002 con el CNA 2008 arroja una disminución en el número de productores, especialmente en las explotaciones con menor superficie operada. De manera correlativa, las explotaciones de más de 10.000 ha observan el mayor incremento porcentual, tanto en número de EAPs como de superficie. Asimismo, por régimen de tenencia de la tierra, se destaca un 5,5\% menos de superficie exclusivamente en propiedad, y se vislumbra un aumento cinco veces mayor del arrendamiento con respecto al contrato accidental ${ }^{4}$.

El departamento de Cruz del Eje representa una de las localidades de referencia geográfica en la zona que acabamos de describir. De acuerdo al último censo de población de la provincia (2010) cuenta con 58.759 habitantes, y, según nuestros cálculos, son 20.999 los pobladores en zonas rurales, que, comparados con los 6.297 existentes en el vecino departamento de Ischilín y los 5.290 del departamento de Punilla, nos permiten concluir que Cruz del Eje conserva el mayor porcentaje de población rural en la región ${ }^{5}$. Respecto al régimen de tenencia de la tierra en el departamento, de acuerdo al CNA '02, los establecimientos agropecuarios con superficies inferiores a 500 ha corresponden al Tipo Social Agrario Familiar Minifundista. Si seguimos estos criterios, de las 1.294 EAPs existentes, un 86 \% (1.111 EAPs) se encontrarían comprendidas en este estrato. La mayoría de agricultores minifundistas no posee títulos de tenencia saneados ${ }^{6}$, por lo que queda muy claro que estos productores familiares se encuentran en inferioridad de condiciones para enfrentar a los actores económicos que aparecen en la zona, cuya influencia y avidez por el recurso tierra genera una disputa marcadamente desigualdad. Una consecuencia de este proceso en el departamento Cruz del Eje es la disminución del número de establecimientos familiares en el período intercensal 88/02 en un $33 \%$ (Hocsman y Preda, 2006, p. 5). Muchos de los "excluidos del campo" (Fornari, 2011) en la región fueron durante gran parte de su vida pequeños productores, o puesteros que desarrollaban tareas productivas y/o de servicios en las haciendas, trabajadores asalariados de grandes explotaciones, entre otros. Y la realidad que encuentran hoy es la de una disminución abrupta en el número de unidades, o, aún peor, el devastamiento del ambiente en el que viven (Trabaglia, 2007; Ensabella, 2008; Preda, 2015), sumado a un "marcado proceso de valorización de la tierra, derivado de la captación de rentas extraordinarias por la puesta en producción de tierras antes no explotadas comercialmente" (Grass y Cáceres, 2017, p. 172) ${ }^{7}$.

Nuestra área de trabajo se ubica en la pedanía Cruz del Eje (con respecto a las otras: Pichanas, Higueras, San Marcos y Candelaria), que ocupa parte del centro del departamento y el extremo norte, de mayor aridez -dada la existencia del salar denominado Salinas Grandes-, y comprende las comunas de Guanaco Muerto, Alto de los Quebrachos, Media Naranja, y los parajes Santo Domingo, San Antonio y El Abra, entre otros de población menor y más dispersa. 
FIGURA 1:

Ubicación provincia de Córdoba, Argentina. Delimitación de la zona de "Ganadería extensiva del Noroeste de la provincia"
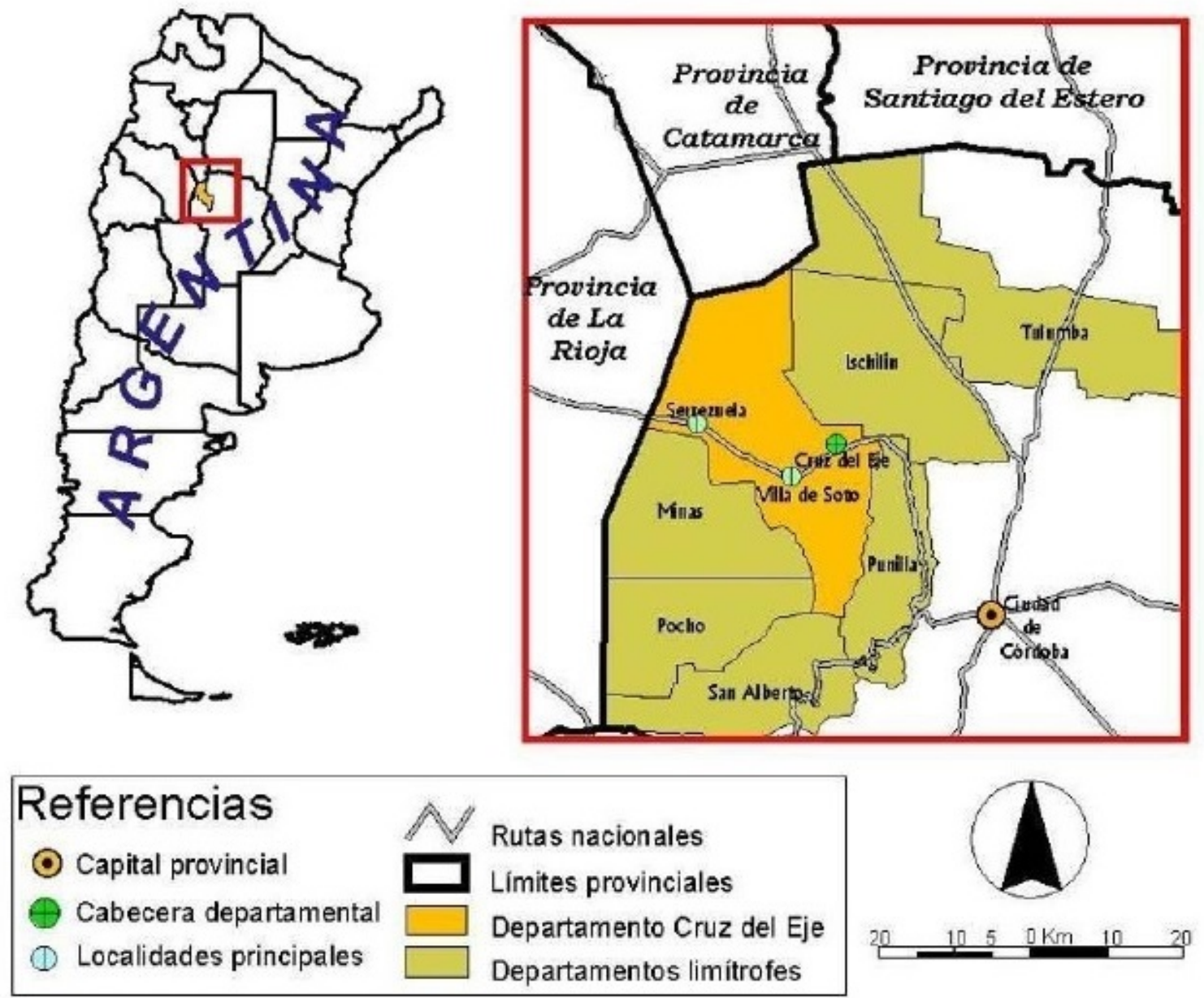

Fuente: Pegoraro et al., 2013

Tal como establecimos en el apartado anterior, desde el punto de vista socioeconómico, las U.D. están subsumidas de forma indirecta al capital por varias razones. Primero, porque el capital no controla directamente el proceso de trabajo doméstico, sino que lo hace indirectamente a través de las reglas de intercambio en el mercado respetando el carácter no capitalista de la producción, y, segundo, dado que si bien existe una subsunción directa cuando el sector doméstico vende su fuerza de trabajo por fuera de la U.D. (al igual que cuando existen transformaciones técnicas en sus actividades), el capital sigue sin controlar directamente los procesos productivos realizados dentro del grupo doméstico.

En este sentido, según los análisis practicados y a partir de nuestro trabajo etnográfico, podemos establecer que la expansión de la ganadería bovina ha generado (y continua generando) un fuerte impacto socioeconómico en todo el departamento Cruz del Eje, y, especialmente, en las pequeñas unidades, puesto que desaparecen los emprendimientos productivos hortofrutícolas (tomates, pimientos, olivares, entre otros) que creaban trabajo para la población local, y en su lugar surgen grandes unidades referenciadas, por lo que alquilan los campos para ganado o especulan según la demanda comercial de otras provincias. A su vez, las otras mediaciones que caracterizan la subordinación al capital de las U.D. cruzdelejeñas se vinculan a la dinámica espacio-temporal de su producción doméstica y a la importancia que ésta reviste en la subsistencia de los grupos. También en el valor que tienen sus relaciones de producción comunitarias en la inserción 
de sus productos en el mercado local y regional, y en el trabajo estacional asalariado para grandes unidades productivas $(\mathrm{Paz}, 2018)^{8}$.

La cría de caprinos constituye la actividad económica más importante de estas U.D., además de lo significativo que resulta el aporte de carne en la dieta familiar, los grupos obtienen la mayoría de sus ingresos a partir de la venta de los subproductos del caprino: la venta de animales en pie (a "bulto") o bien la leche residual, el pelo y cueros. Los destinos comerciales del cabrito en la zona, luego del autoconsumo y la reposición de madres, son: venta a los "cabriteros" (intermediarios de los frigoríficos), comercialización a través de las redes creadas por la Organización zonal Cruz del Eje perteneciente al Movimiento Campesino de Córdoba-MC-, y venta a consumidores finales ${ }^{9}$.

La producción agrícola se realiza fundamentalmente en el período cálido y lluvioso, lo que redunda en una concentración de trabajo estacional desde noviembre a mayo, meses en los cuales se realiza la siembra, cosecha y recolección. Los principales cultivos son: maíz, zapallo, cebolla, acelga, tomate, pimiento, sandía, melón, entre otros. Y su venta se realiza a través de los "puesteros del mercado", que los buscan en el campo para llevarlos a Cruz del Eje, a Córdoba, o a verdulerías minoristas de la ciudad. También a través de cooperativas agrícolas de la zona.

Por otro lado, ante la situación de conflicto por el acceso a los recursos que atraviesan actualmente estas comunas (cuestión que se vio agravada durante la sequía de años anteriores), los lazos comunitarios y de reciprocidad adquieren gran importancia: se comparten tanto las represas de agua (que pasan a ser comunitarias) para regar los sembradíos en los espacios dentro de zona, como las "largadas" y piletas de baño entre los crianceros de los espacios fuera de zona de riego, y también las herramientas y productos para controlar plagas y/o parásitos e infecciones de animales y plantas. A su vez, las ventas al menudeo en las comunas y parajes, a la vera de la ruta o en las fiestas, son realizadas -de acuerdo a nuestro registro- por las mujeres, en lo que hemos definido como un acto de especialización de género dentro de los grupos de la región. Desde luego, más comunes son los regalos entre parientes y vecinos, de carne, grasa, productos de huerta, frutas, y de algunos productos hechos artesanalmente, como dulces y arropes (Paz, 2018, pp. 182, 185, 189).

Ahora bien, tales referencias son útiles pero resultan limitadas para explicar los espacios de relativa autonomía que estas unidades tienen para enfrentar los mecanismos de explotación en la región considerada. En tal sentido, observamos que la situación de "cuasi exclusividad" de la que gozan los intermediarios que circulan por el campo fue modificada en la última década gracias a la acción del Estado nacional y sus instituciones, como el Instituto Nacional de Tecnología Agropecuaria (INTA) con su programa "Cambio Rural" y el Instituto Nacional de Tecnología Industrial (INTI). Allí se realizan actividades de capacitación productiva y de estrategias de venta para que las pequeñas U.D. puedan mejorar la comercialización de sus productos. A su vez, mencionamos las redes igualitarias de intercambio que originó el MCC con su Organización zonal Cruz del Eje. El accionar de la Red de Comercio Justo 10 fue desplazando a los mercachifles, especialmente a los "cabriteros", que visitaban las comunas y parajes. La Red genera intercambios que permiten proveer a los productores asociados algunos elementos necesarios para su subsistencia hasta el momento en que logran colocar su producción (principalmente, los cabritos). Lo importante es que el énfasis de los miembros de la Red está puesto en trascender los aspectos estrictamente económicos y, sobre todo, en fomentar entre los productores, a partir de modelos participativos y comunitarios, el desarrollo de prácticas solidarias. Los pequeños productores presentan distintos grados de integración a la Red (como así también al MCC en su Organización zonal Cruz del Eje). Algunos de ellos participaban activamente en reuniones, trabajos de selección y limpieza de cueros, envasado de salsa de tomates, etc., mientras que para otros resultaba simplemente un canal de comercialización alternativo. Muchos de los pobladores locales, empero, siguen optando por vender una parte importante de su producción a los intermediarios.

En relación al recurso hídrico, el MCC considera que el derecho al agua está en peligro en la región. Según lo argumenta en un documento del año 2009: 
Ríos y canales se vienen entregando al uso de privados que escamotean o contaminan el agua de todos. Así, las cuencas de sierras y zonas turísticas también se afectan por el avance del negocio inmobiliario de las firmas empresarias afines al gobierno (...) empresarios agropecuarios han privatizado de hecho las aguas de los Ríos Dulces, bajo el amparo de la gestión provincial, mientras que la sequía arrecia aguas abajo a las vacas y los caballos que mueren empantanados sobre el lecho del río" (MCC, 2009, pp. 13-14).

Acceder al agua con seguridad y cantidad representa, de acuerdo al MCC, "afianzar las vidas de estas comunidades en el campo, mantener vigente su estilo de producción respetuoso con el monte y con el entorno, conservar las tradiciones de sus antepasados, su cultura (...) mantener vivo todo lo que identifica a estas familias campesinas". (MCC, 2009, p. 17). Como resultado de esta situación, observamos en nuestra área de estudio la existencia de una gran heterogeneidad de intereses comunes y encontrados, con diferentes tendencias productivas y conflictos por la apropiación de un recurso vital pero escaso: el agua. Tal como analizaremos en el apartado siguiente, luego de la construcción del dique Cruz del Eje, a lo largo del tiempo, "las familias cruzdelejeñas ubicadas en los espacios más vulnerables del departamento, fueron perdiendo el control y el manejo directo sobre el líquido vital lo que provoca un impacto profundo sobre sus sistemas productivos de subsistencia" (Fleitas y Paz, 2012, p. 46). Sin duda, existen resistencias comunitarias, asistencia técnica, subsidios y ejecución de proyectos del gobierno nacional que se proponen, desde los objetivos formales, "beneficiar" a los sectores históricamente relegados en la región. Si suponemos que fuera factible identificar como idóneas estas acciones, ¿̇resultan suficientes para que el acceso al agua sea equitativo entre las pequeñas U.D. y las grandes unidades productivas cada vez más numerosas en la región? En principio, parece más razonable indagar acerca de cuáles son las consecuencias que acarreó la construcción del dique en la región, vinculándolas con un análisis más detallado de los cambios operados en las condiciones de la distribución del agua entre las poblaciones campesinas de Cruz del Eje durante las primeras décadas del siglo XXI.

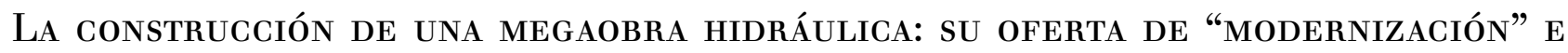 INCREMENTOS DE PRODUCTIVIDAD PARA LA REGIÓN}

A partir de la investigación de una realidad a escala local, encontramos que en el noroeste de la provincia de Córdoba, Argentina, la propuesta de construcción de un dique para incentivar el desarrollo económico y el mercado local se expresó en el proyecto estatal denominado Dar agua al norte, lanzado a mediados de la década de 1930 y ejecutado en los años cuarenta. El proyecto se enmarcaba en el programa económico de desarrollo propuesto por el entonces gobernador Amadeo Sabattini (1936-1944). Este programa admitía ribetes "vanguardistas" para la época, en tanto sostenía ideas que luego serían propuestas por la Comisión Económica para América Latina y el Caribe (CEPAL) en los años cincuenta, basadas en las estrategias de la sustitución de importaciones (ISI), y otras medidas que permitieran superar la condición de dependencia y subdesarrollo que ubicaba a estas regiones como meras productoras de materia prima.

El gobernador Amadeo Sabattini (del partido de la Unión Cívica Radical) representaba el ala modernizadora del partido, con una ideología orientada hacia la social democracia e inspirada en el laborismo inglés, y proponía realizar una industrialización primaria sobre la base de un régimen en la propiedad de la tierra asentado en las pequeñas explotaciones, tal como de hecho existían en la provincia (Tach, 1991). En este sentido, durante su mandato, Sabattini impulsó obras públicas para la justicia social, la asistencia sanitaria, y concretó así lo que había declamado en su programa de campaña: "Caminos para el Sur" y "Agua para el Norte”. Y a través de la creación de la Dirección General de Hidráulica (DGH, 1938) posibilitó la construcción de grandes diques como el Nuevo San Roque, dique la Viña, el dique Cruz de Eje y el dique Los Alazanes. En sus palabras a la asamblea legislativa provincial, expresaba:

El proyecto que pronto se convirtió en la Ley 3732 (...) inspirada en el deseo de llegar por el camino más seguro a la construcción de los diques que más urgencias revestían (...) se ha afirmado con una era progresista para la provincia. (...) para 
responder a la lógica impaciencia de los vecinos de Cruz del Eje, se puede expresar que jamás se ha descansado en las tareas de llevar adelante el proyecto del Dique, cuya necesidad es cada día más evidente (Sabattini, 1992, p. 70).

Según el gobernador, se efectuaron "importantes estudios y trabajos en el propio terreno y en los gabinetes” (Sabattini, 1992, p. 132). Pero, ¿en qué consistió la obra? Brevemente, se inició en marzo de 1940 y se terminó en diciembre de 1943, comenzó a embalsar en noviembre del mismo año y llegó a emplear a 600 obreros. De acuerdo al ingeniero civil que dirigió la construcción, Benjamín Reolín:

La zona de regadío ocupará una extensión apreciada entre 22.000 ha, de las cuales unas 8.000 ya recibían el riego sumamente aleatorio debido a la gran irregularidad de los caudales aportados (...) la obra contará con un dique nivelador y canales maestros de $1 \mathrm{~km}$ cada uno en cada margen del río (...) uno de los sistemas troncales más perfecto de su género, pues todos los canales van revestidos (Reolín, 1945, pp. 5-7).

Respecto a la cita presentada en el párrafo anterior, sin duda que desde el punto de vista político y técnico, la construcción del dique era estratégica por varias razones. En primera instancia, por la cercanía de ciudades turísticas como Capilla del Monte, la Cumbre, La Falda, etc., que se verían "favorecidas" con el aumento de producción agrícola-ganadera de las ahora irrigadas tierras cruzdelejeñas. En segundo lugar, porque la zona rodeaba el nudo ferroviario del Estado y red caminera de primer orden. Aunque, si suponemos que el proyecto comportaba beneficios en tales disposiciones, es decir, de manera sistémica, ¿resultó eficiente para la población local?

FIGURAS 2 Y 3:

Construcción del Dique Cruz del Eje, Año 1943

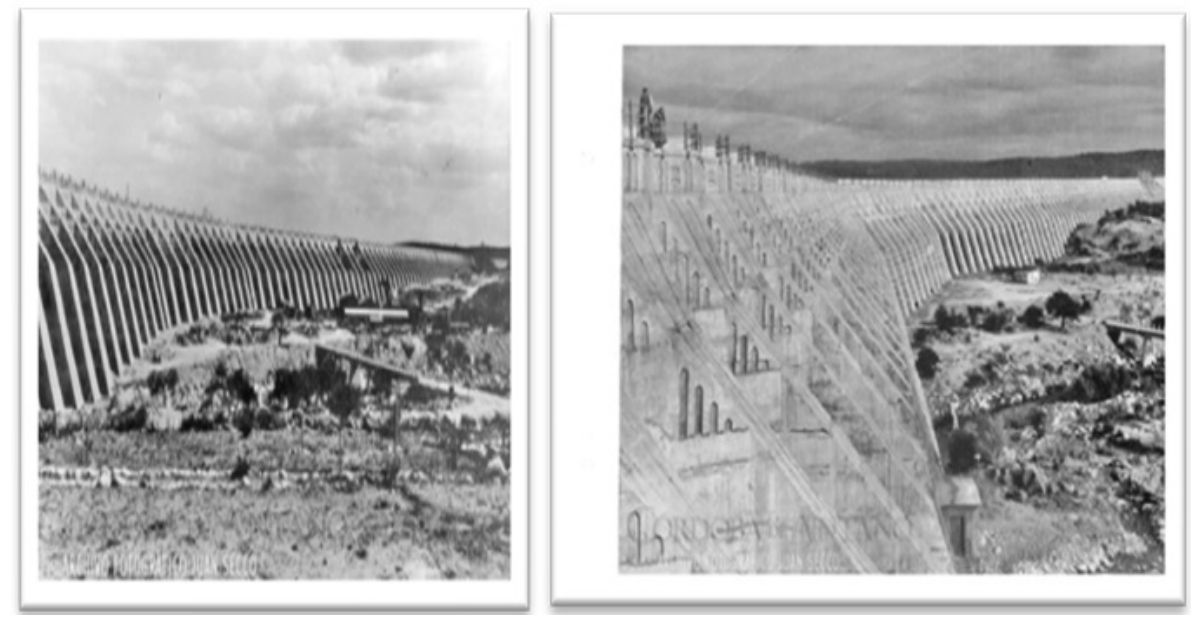

Fuente: Archivo personal de las autoras.

Desde la perspectiva adoptada en este artículo, es relevante reiterar que la planificación de grandes obras hidroeléctricas tiene sus intencionalidades económicas y políticas sujetas a las ideas de "progreso" y "salto hacia adelante", que son justificadas a partir del argumento del desarrollo productivo en las regiones donde se realizan (Balazote y Moreyra, 2005, p. 51). En este sentido, según las afirmaciones sostenidas por ingeniero civil que guio la construcción del dique Cruz del Eje, la obra respondía al deseo de elevar la población y el consumo de las localidades cercanas, para fomentar el mercado local y su "potencial turístico". Desde luego, la puesta en práctica del proyecto fue vista por los pobladores locales como positiva, ya que suponía beneficio e incentivo a la producción local. Empero, y aunque estas obras varíen según su naturaleza, la importancia para la región y las particularidades históricas y culturales donde se realizó el emprendimiento del mencionado dique pueden ser cuestionadas, no por el valor de la obra en sí misma como por la intencionalidad subyacente del proyecto que no dejaba claro quiénes serían los "reales" beneficiarios y quiénes los afectados. Y esta cuestión adquiere mayor sentido si se tiene en cuenta que, a comienzos del presente siglo, las U.D. campesinas 
situadas en la margen izquierda del embalse Cruz del Eje reciben riego en forma eventual y pagan precios costosísimos por su aprovisionamiento, tanto para consumo como para producción ${ }^{11}$. Por este motivo, apuntamos a poner de relieve que la estrategia seguida por el gobierno provincial en dicha construcción siguió, en líneas generales, pautas análogas a las del resto de América Latina en este tipo de emprendimientos ${ }^{12}$, y que una de las más graves consecuencias al respecto es el problema de la distribución inequitativa del recurso hídrico en la región.

\section{EL AGUA EN CRUZ DEL EJE Y LAS EXPLICACIONES SOBRE SU REDISTRIBUCIÓN CONTEMPORÁNEA}

El sistema de regadío por canales es la fuente principal para el desarrollo de cultivos y abrevaderos de animales en las zonas rurales del departamento Cruz del Eje. En tal sentido, conviene aclarar que en los documentos oficiales de la construcción del dique se planteaba que la "ineficiencia de las incontables acequias sería resuelta por el revestimiento completo y magistral de todos los canales de la obra" (Reolìn, 1945, p. 11). Por lo señalado, es lógico suponer que los problemas de los pequeños productores para que el agua llegue a las represas familiares no serían a causa del estado inefable de los canales. Sin embargo, no es la situación que encontramos en la actualidad, dado que las U.D. campesinas tienen dificultades para el autoabastecimiento, y la situación se agrava en las comunas y parajes que cuentan con riego eventual, las cuales resultan las más condicionadas para la producción y reproducción social de sus unidades.

La cuenca hídrica más importante en el departamento Cruz del Eje es la de nombre homónimo que, a su vez, está conformada por dos sub-cuencas: la del Río Cruz del Eje, Río Soto y la del Río Pichanas. El dique posee una cota que, cuando es alcanzada, permite la entrega de agua para riego en aproximadamente 13.000 hectáreas. Y, conforme a la situación del dique en los primeros meses de cada año, el gobierno provincial planifica el uso del agua, y personal de la Empresa Provincial de Energía de Córdoba -EPEC- efectúa su entrega mediante la apertura de las compuertas del dique según sus indicaciones. Cuando la cota mínima determinada para el dique es superada, la diferencia se entrega para ser distribuida en los espacios "fuera de zona", donde actúan entidades informales, conformadas ad hoc por productores, jefes comunales, que se ocupan del denominado "riego eventual" (Bergamin et al., 2010).

Según sostienen Gerardo Bergamín y otros ${ }^{13}$, al presente "se está aún lejos de un manejo integral de la cuenca", pues a factores ecoambientales -como el bajo régimen de precipitaciones, aguas superficiales escasas con alta infiltración, acequias en mal estado de conservación, suelos agrícolas de calidad media con una amplia superficie de suelos pobres- se añade la situación de que "el agua para regadío está mal gestionada por parte del Estado provincial y las instituciones públicas encargadas de distribuir este bien social" (Bergamín et al., 2010, p. 17).

De acuerdo a las investigaciones de los autores mencionados y a nuestro relevamiento, tanto la infraestructura como el manejo del agua de los grandes productores de materias primas para exportación resulta deficiente a nivel provincial y a nivel individual. En efecto, y como ya hemos señalado, en la región del noroeste de Córdoba se está produciendo el avance de la frontera agropecuaria, lo que implica un aumento de la producción ganadera de cría, recría e inclusive de invernada. Tanto los grandes productores como las asociaciones empresariales que los representan (ligadas a la Sociedad Rural Argentina) buscan concentrar la propiedad del agua desde otro modelo productivo (producción de alfalfa bajo riego) que aquel sostenido por las históricas U.D. de la zona. Pero, ¿cómo se expresa en la dinámica cotidiana de estas últimas tal jerarquización sobre el recurso hídrico? Brindar una explicación más comprensiva de tal fenómeno demanda ampliar el análisis al comportamiento de los pequeños productores que habitan fuera de zona de riego, y analizar las dinámicas y tensiones que vivencian, ya sea por la falta de agua como por la imposibilidad de permanecer en sus comunidades. 


\section{LOS ESPACIOS FUERA DE ZONA DE RIEGO: PRODUCCIÓN Y REPRODUCCIÓN SOCIAL CONDICIONADAS}

Si bien no contamos con una definición específica de los "fuera de zona", reconocemos que se trata de áreas con riego eventual, ubicadas a $50 \mathrm{~km}$ del paredón del dique extendido a ambas márgenes del río Cruz del Eje. Estos espacios son los últimos que reciben el agua para riego y para consumo, y las obras se encuentran en deplorables condiciones, porque en el trayecto de las canalizaciones hacia los predios se observa el derroche constante de las aguas. Se estima que el $60 \%$ del líquido se pierde a causa de las filtraciones y de la evaporación (Fleitas y Paz, 2012).

FIGURA 4:

Aspecto del canal Provincial (Ramal 1) que pasa por Iglesia Vieja, departamento Cruz del Eje, Córdoba

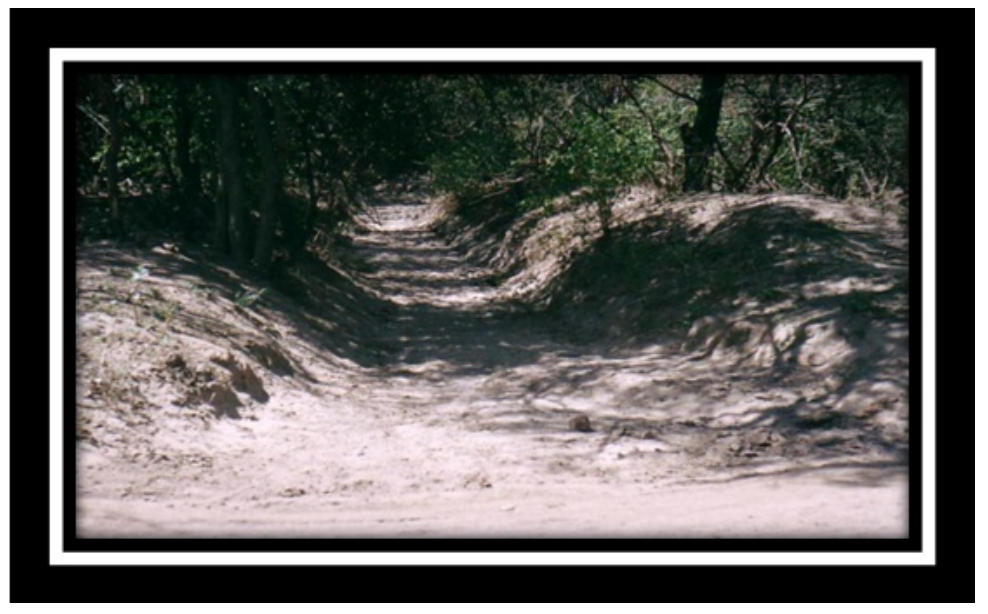

Fuente: archivo personal de las autoras.

Según nos manifestó el secretario de recursos hídricos del recientemente creado Ministerio de Agua, Ambiente y Servicios Públicos de la Provincia de Córdoba:

Son zonas eventuales donde los usuarios pagan por hora. A cada margen le corresponde una comisión (...) no existen las reglamentaciones para los fuera de zona, nadie está empadronado en los fuera de zona. En el mes, el sistema de dar agua es mediante tres turnos y se divide la distribución entre los que van hacia las represas (hasta $30 \mathrm{~mm} 3$ ). Pero para fuera de zona se dispone de $4 \mathrm{hm} 3$. Si son más de 33, se les puede dar más $-6 \mathrm{hm} 3$ - para que lo usen en el riego (Secretario de Recursos Hídricos, Cruz del Eje, Córdoba. Septiembre de 2015).

Aun cuando la lectura de esta declaración de un funcionario público permite captar cierta relación positiva entre la distribución del agua en las represas -y de acuerdo a si se necesitase para consumo familiar o producción-, es posible observar que estas familias no están incluidas en los sistemas de gestión. En el caso particular indagado, la distribución del agua de riego es, por ley, función de los consorcios creados a tal fin. La pedanía Cruz del Eje cuenta con un consorcio llamado Usuarios de Riego del dique Cruz del Eje, que nuclea a aproximadamente 400 productores ${ }^{14}$. Entre las acciones lideradas por el consorcio se registra el mantenimiento de los canales secundarios a través de los cuáles el agua entra a los sistemas de producción, por lo cual la eficiencia del uso del agua es responsabilidad exclusiva del productor. En el caso de los espacios dentro de zona de riego, el agua llega bien. De acuerdo con C., un pequeño productor frutihortícola que habita en la comuna de Media Naranja: "aunque se pierde una parte porque los canales están muy destruidos, el agua llega más o menos bien" ${ }^{15}$. Por el contrario, en los espacios fuera de zona, cuyo sistema de riego predominante a nivel de predio es, en el 80 \% de los casos, "por manto" o "por surcos", las pérdidas por evaporación y por el estado de infraestructura de los canales son muy altas. Asimismo, y como hemos advertido, en su distribución no actúa el Consorcio de Regantes, sino una serie de entidades 
informales, conformadas ad hoc por los pequeños productores. También los jefes comunales se ocupan del riego eventualmente. Así lo explica un pequeño productor de Guanaco Muerto, comuna ubicada fuera de zona de riego:

Acá son siempre 3 riegos los que nos dan por año, pero después de eso, el agua la traen cada dos meses, cada 6 meses para la represa y a nosotros nos dan para regar un pedacito. Hay como 3 o 4 represas, nada más. Están en el medio de los campos (...) El jefe comunal manda a algún chico con un cuaderno y ahí pregunta: “¡cuántas horas querés vos?, ¿cuántas horas querés vos?”, y así todos van diciendo y él anota: suponte que somos 10 regantes y entre todos pedimos $100 \mathrm{o} 200$ hs de agua, dependiendo si llueve. Y eso puede durar un mes, un mes y medio. Pagamos \$30 [USD ,077] por hora (R., pequeño productor de 57 años. Guanaco Muerto, Agosto de 2015).

El aspecto mas destacado que evidencia la alocución es que los pequeños productores de estas zonas dependen de su propia organización (a nivel vecinal, y a nivel de la producción), y de la buena voluntad del jefe comunal (quien es el encargado de pasar el pedido a la Secretaría de Recursos Hídricos) para obtener el líquido vital y garantizar su subsistencia. Según lo expresa N., una campesina que habita en el paraje Santo Domingo, paraje fuera de zona de riego ubicado en el límite de las Salinas Grandes:

Para los animales usamos el agua de la represa y cuando se termina hay que esperar que llueva. Nosotros estamos fuera de la zona de riego, nos llega muy poca agua (...) La represa la llenamos con el pozo que es de napa freática y la sacamos con el generador... si no se seca, tenés agua. A veces se agota pero no se acaba. Ya cuando se acaba tenés que esperar que llueva (N., pequeña productora, 52 años. Santo Domingo, Cruz del Eje, Octubre de 2015).

La información vertida por nuestros entrevistados sugiere, por una parte, que el agua para consumo en estas comunas y parajes se obtiene a través del sistema de perforaciones o "pozos" (bombas que extraen el agua de las napas freáticas). Empero, las perforaciones son de dominio público, y las bombas para extracción son muy pocas ( 2 en Guanaco Muerto, 1 en San Antonio) y pagan cánones altos para poder consumirla (de acuerdo a nuestro relevamiento, $\$ 100$ [USD 2,57] mensuales) ${ }^{16}$. Cada familia saca la cantidad necesaria de agua y la conserva en un tacho y la utiliza para cocinar y para beber. El agua que llega a la represa también se almacena en un tacho por espacio de dos días y ese líquido es el que utilizan para higiene personal, lavar ropa, utensilios y para las gallinas. Por otra parte, el agua que llega a los predios para que las familias llenen las represas y rieguen sus cultivos es de pésima calidad, ya que arrastra arena fruto de la erosión en el lecho de los canales de tierra. Así lo manifiesta R., pequeño productor cabritero de la Comuna de Guanaco Muerto:

Hay veces que te largan 300 litros de agua en la punta del canal, pero cuando el agua cae a la acequia de tierra, se resume, y ya no llega la misma cantidad (...) Ahora me dijeron que me iban a dar agua, y no me ha alcanzado para terminar de regar. Se me cortó el viernes y me ha quedado un pedacito de la chacra sin regar. No nos queda otra que esperar que llueva porque puede pasar un mes, dos meses hasta que nos vuelvan a dar (R., pequeño productor de 57 años. Guanaco Muerto, Agosto de 2015).

La situación descripta, complementada con los datos referidos a la gestión la del agua en la cuenca hídrica de Cruz del Eje, revela que el líquido vital ha pasado de ser un bien social a un bien económico en la región, lo que dejó en evidencia los problemas estructurales para la producción y las condiciones de vida material de los regantes campesinos. Sin embargo, cabe preguntarse cuál es el impacto que la escasez de agua tiene en la reproducción social de estos grupos ${ }^{17}$. Para dar una respuesta parcial a este interrogante recurrimos a la confección de algunos indicadores específicos (elaborados sobre la base nuestro trabajo de campo y de variables de análisis) que permiten visualizar que la tendencia a la diferenciación entre los grupos con acceso al agua y aquellos que no lo tienen se verifica acentuada en los últimos años. Respecto a la alimentación, si se toma como indicador el nivel de consumo en la dieta diaria y su contenido, en las U.D., dentro de zona de riego, la diversificación de la producción es mayor, y, por lo tanto, aumenta la incidencia de otros consumos, tales como hortalizas y frutas. Contrariamente, los grupos domésticos con riego eventual tienen una dependencia cuasi del $100 \%$ en sus economías de la venta de cabritos, y sólo algunas familias pueden mantener sus huertas o frutales. Por esta razón, sus ingresos monetarios se ven reducidos, pero, sobre todo, se ve afectado su balance dietario. 
La situación descripta conlleva a otra cuestión práctica de diferenciación, pues en las U.D. dentro de zona de riego el jefe de familia trabaja principalmente como peón rural y la mayoría de los grupos domésticos practican la agricultura, especialmente de hortalizas, y alfa y algunos cereales como avena y también frutales como el tomate. En las U.D. fuera de zona de riego, en cambio, existe el desarrollo mayoritario de una ganadería autóctona (cabras), y los pequeños productores independientes que viven de ello rara vez recurren al trabajo fuera de la unidad. Es decir, el trabajo asalariado es más frecuente en las U.D. dentro de zona de riego, pues la agricultura demanda menos tiempo de ocupación y las actividades principales son llevadas a cabo por las mujeres y niños del grupo. Por el contrario, la ganadería extensiva de cabras es una actividad demandante, especialmente ahora que los campos están alambrados y hay que controlar que las cabras no se metan en terrenos privados.

En cuanto a los lazos de parentesco y el indicador de la contratación de mano de obra en momentos claves del ciclo productivo (de agosto a diciembre), se revelan algunas diferencias notables entre ambas zonas. Las U.D. conformadas por una familia nuclear y las relaciones de parentesco prácticas -que no recurren a contrataciones por fuera del grupo doméstico- tienen mayor relevancia en las áreas de riego eventual, donde, a su vez, apreciamos una diferenciación del sector campesino menos acentuada. En cambio, en los grupos domésticos dentro de zona de riego observamos que cobran mayor importancia los lazos de complementación entre familias y/o individuos no emparentados entre sí. Es frecuente la construcción de relaciones prácticas no filiales, lo que significa que estas familias campesinas tienden a complementar su trabajo con el de otras personas, y aun ello suele combinarse con la venta de la fuerza de trabajo de alguno/s de sus miembros en las medianas y grandes unidades productivas de la región.

Finalmente, el problema que se presenta es que en las tierras de riego eventual se torna casi imposible cultivar o mantener animales de la chacra (aves de corral, chanchos), pues el agua adjudicada es solo para las represas. De esa agua, una gran cantidad, como hemos advertido, se evapora en el verano por las altas temperaturas o se pierde por la pésima condición de los canales. A estas familias no les está quedando otra opción más que la de migrar a los centros urbanos, mayoritariamente a la ciudad cabecera del departamento o a Córdoba, la capital provincial. Así lo refieren los miembros de estas U.D.: "Estamos pasando tiempos difíciles (...) a esto se llegó porque el agua va solo a los dentro de zona, entonces acá no se puede sembrar, y no hay trabajo" (N., pequeña productora, 52 años. Santo Domingo, Cruz del Eje, Octubre de 2015); "La que trabaja es la hija que se quedó con nosotros. Ella trabaja en la Comuna, los otros 5 están en Córdoba, se fueron a buscar trabajo porque aquí no había trabajo. No hay qué hacer acá (R., pequeño productor de 57 años. Guanaco Muerto, Agosto de 2015).

Ahora bien, la monopolización del recurso hídrico -así como de la tierra- es una consecuencia del mencionado proceso de avance de la frontera agroganadera, cuya tendencia ascendente obedece a un fenómeno estructural. Sin dudas, esto afecta a los sectores más vulnerables del agro, como lo son las explotaciones más pequeñas y con menos recursos, pero también las unidades que cuentan con un buen nivel de irrigación y en tierras de mejor calidad se están viendo afectadas. Esta situación obliga a los pequeños productores locales a tomar la opción de arrendar sus campos. En palabras de C., un productor frutihortícola que habita dentro de la zona de riego:

Yo tenía en mi campo de 15 has, 5 con olivos y hoy le pasé la topadora a casi todos. Eran los olivos que había plantado mi abuelo. ¿Cuál es el problema? El aceite de oliva cuesta un montón y la materia prima no vale nada. Y lo mismo pasó con el tomate: ¡se fueron los costos al diablo! (...) Así que, la idea es arrendar. Somos poquitos los autóctonos productores de la zona, y yo debo ser el más joven: todos los de mi generación han abandonado, se han retirado (...) es mucho sacrificio, y no están cerrando los números (C., pequeño productor fruti-hortícola de 48 años. Media Naranja, Octubre de 2015).

El resultado de las cuestiones analizadas nos permite identificar algunos de los principales problemas para las U.D. cruzdelejeñas. Como hemos venido sosteniendo, los grandes propietarios de la región, foráneos en su mayoría, están todos empadronados y con sus papeles al día, por lo cual van acaparando las tierras de mayor calidad y consumen mayor cantidad de agua por el total de hectáreas productivas. A ninguna de las pequeñas 
U.D. que presentamos en este trabajo las favorece dicha situación. Pero, ¿sería apropiado concluir que la presión de los grandes productores foráneos es la única con capacidad de condicionar la reproducción social de estos grupos domésticos? De ningún modo. A las causas presentadas, debemos sumar los mecanismos de presión que ejerce el Consorcio de Regantes frente a la secretaría de Recursos Hídricos, los gobiernos municipales y, básicamente, la intervención o no del Estado, que deja en situación de vulnerabilidad a una parte de su población. Las acciones, entonces, quedan reducidas a "favores legales" y beneficios cada vez mayores orientados a los intereses de quienes detentan el poder económico y simbólico, en desmedro de los intereses y necesidades de las pequeñas unidades productivas que aún habitan la zona estudiada.

\section{Conclusión}

Más allá de la dificultad encontrada para discriminar con precisión las operaciones -tanto directas como indirectas- para el avance territorial del capital en detrimento de las familias campesinas, se aportó evidencia parcial demostrativa de que el departamento Cruz del Eje es uno de los tantos casos locales, en el que se observan modalidades de avance del capitalismo agrario sobre economías domésticas.

Asimismo, la información reunida sobre la construcción del embalse Cruz del Eje y la planificación para parcelamiento y riego reveló que su magnitud no alcanzó dimensiones suficientes para lograr una redistribución equitativa del líquido vital en todo el territorio. En este sentido, si bien el programa Dar agua al norte estuvo nutrido de componentes ideológicos modernizadores, observamos que en definitiva, se utilizó la realización de esta gran obra para la autolegitimación del gobierno provincial de la época, antes que para el mejoramiento del nivel de vida de los pobladores locales. Esta afirmación no supone que con posterioridad el dique no irrigaría una mayor cantidad de hectáreas que las que irrigaba antes de su construcción, sobre todo si se toma en cuenta la cantidad de litros que logró embalsar y la mejoría experimentada en las ciudades turísticas como La Cumbre, La Falda, por el acceso al agua potable en la segunda mitad del siglo XX. De todos modos, la forma que adquirió la distribución del agua en la zona sugiere la necesidad de atenuar la caracterización del paradigma que sustentó la construcción del mencionado dique: "eficiencia e intento de modernizar el sector" (Reolín, 1945, p. 16), pues el apoyo decidido a la gran propiedad con la consecuente implantación diferencial entre "recursos públicos" y "privados", en donde se puede ser "propietario" de los segundos y "usuario" de los primeros, deslegitiman plenamente esa declaración.

Con este cotejo no se cuestiona el papel que para el desarrollo de la región jugó la construcción del embalse Cruz del Eje. Se apunta, en cambio, a poner de manifiesto que en el departamento de nombre homónimo fue menor por razones específicas. En primer lugar, porque sus tierras, en general, no fueron aptas para la producción de bienes para el mercado mundial, sino más bien para el abastecimiento del mercado interno. Segundo, no existió un plan integral que contemplara la pequeña producción familiar, ni la eficiencia de los cultivos y el manejo sustentable que pudieran realizar las familias campesinas en el territorio. Tercero, al establecer los espacios fuera de zona de riego, se naturalizó la ubicación marginal de las comunas y parajes ubicados en dichas tierras.

En otra dirección, a lo largo del trabajo se pusieron de manifiesto los efectos provocados por el avance de la frontera ganadera en la región. Si bien como consecuencia de esto los espacios de riego eventual se fueron convirtiendo en territorios de disputa, también resultan severamente afectadas las U.D que se encuentran en espacios dentro de zona de riego, dado que el consorcio de regantes y los gobiernos locales favorecen a los grandes productores ganaderos presentes en la región. Así, se verificaron dos situaciones. Por un lado, la ausencia de una coordinación interinstitucional que articulara los intereses de los sectores más vulnerables del departamento y convocara a instancias públicas locales donde las cuestiones ambientales y productivas de las pequeñas U.D. puedan visibilizarse. Por otro lado, constatamos que la región cuenta con potencialidades que podrían colaborar a revertir el panorama que presentamos, a saber: la existencia de los diques Pichanas y Cruz del Eje, así como las Sierras y los bosques protectores con un valor ecológico y natural inigualable; la 
presencia de agua subterránea y una amplia zona de canales para regadío que sólo necesitan revestimiento y administración adecuada y equitativa; la representación de organizaciones comunitarias-campesinas como APENOC y la Organización zonal Cruz del Eje, pertenecientes al Movimiento Campesino de Córdoba (MCC). Además, estas características, propias de la heterogeneidad de la región, pueden determinar una riqueza productiva en el ámbito agropecuario, y garantizarían una mayor diversificación, por ejemplo, en el área frutihortícola (lo que redundaría en mayores puestos de trabajo), pues, como planteara el ingeniero Reolín en el año 1945, las tierras existentes en la zona son "reputadas inigualables para toda clase de cultivos subtropicales".

\section{Bibliografía}

Archetti, E., y Stölen, K. A. (1975). Explotación familiar y acumulación de capital en el campo argentino. Buenos Aires: Siglo XXI.

Balazote, A., y Moreyra, A. (2005). Disputas territoriales y control de recursos hídricos en parajes de la localidad de San Martín de los Andes. En M. J. Reis, J. C. Radovich y A. Balazote (Editores), Disputas territoriales y conflictos interétnicos en Brasil y Argentina (pp. 47- 68). Córdoba: Ferreyra Editor.

Barkin, D. (2001). Superando el paradigma neoliberal: desarrollo popular sustentable. En N. Giarracca (Compiladora), ¿Una nueva ruralidad en América Latina? (pp. 81-102). Buenos Aires: CLACSO y ASDI.

Barri, J. (2013). Reflexión Crítica sobre el Uso del Concepto de Subsunción Mediada en el Estudio de la Cuestión Campesina. Astrolabio (Nueva Época), 11, 221-247.

Bartra, A. (1982). La Explotación del trabajo campesino por el capital. México: Macehual.

Bergamín, G.; Ryan, S.; Bisio, C.; Re, G.; Menna, J.; Ramos, C.; Prado, A.; Becerra, V.; Isally, C. y Ricotto, A. (2010). La Gestión del Agua y la Ordenación Territorial para un desarrollo sustentable. El caso de la Cuenca de Cruz del Eje. VII Congreso Latinoamericano de sociología Rural, Porto de Galinhas, Brasil. 20-24 de noviembre.

Bourdieu, P., y Passeron, J. C. (1995). La reproducción: elementos para una teoría del sistema de enseñanza. México: Fontamara.

Bustos, R. M., y Yañez, L. (2004). Conflicto social y lucha simbólica: la disputa por el agua en los sistemas de riego de Mendoza. VII Congreso Argentino de Antropología Social, Córdoba. 25-28 de mayo.

Cabido, M., y Zak, M. (2010). Deforestación, agricultura y biodiversidad: apuntes sobre el panorama global y la realidad de Córdoba [online]. Universidad Nacional de Córdoba. Disponible: en: http://www.unciencia.unc.edu.ar/201 $0 /$ junio/deforestacionagricultura-y-biodiversidad-apuntes

Carruthers, D. (Editor.) (2008). Environmental Justice in Latin America. Problems, Promise and Practice. London: The Mit Press.

Chayanov, A. (1974). La organización de la unidad económica campesina. Buenos Aires: Nueva Visión.

Dávila Ladrón de Guevara, R. (2011). Estrategias futuras de desarrollo rural, Pontificia Universidad Javeriana-Facultad de Estudios Ambientales y Rurales, Instituto de Estudios Rurales. Recuperado de http://www.javeriana.edu.co/i er/?idcategoria $=109$

Ensabella, B. (2008). El deterioro de los ecosistemas del norte cordobés y los límites de las economías campesinas. Mundo Agrario, 9(17), 1-20.

Escobar, A. (2007). La invención del Tercer Mundo. Construcción y deconstrucción del desarrollo. Caracas: El perro y la rana.

Fleitas, K., y Paz, M. (2012). Problemática del agua e impacto social en las familias campesinas del noroeste cordobés. Cuadernos de Antropologia, Nro. Especial, 39-62. Recuperado de http://www.proarhep.com.ar/2014/09/02/c uadernos-de-antropologia-nro-especial/

Ghida Daza, C.; Sánchez, C. (2009). Zonas Agroeconómicas Homogéneas: Córdoba, área de influencia de la EEA INTA Manfredi. Cartilla Digital Manfredi No. 3. Recuperado de http://www.inta.gov.ar/manfredi/info/bole tines/cartilla_dig_manfredi/cartilla_digital_1_08.htm 
Gordillo, G. (1992). Cazadores-Recolectores y cosecheros, subordinación al capital y reproducción social entre los Tobas del Oeste de Formosa. En H. Trinchero, F. Pichinini y G. Gordillo (coords.), Capitalismo y grupos indigenas en el Chaco Centro-Occidental (pp. 75-105). Buenos Aires: CEAL.

Gordillo, G. (2006). En el Gran Chaco: Antropologias e historias. Buenos Aires: Prometeo.

Grass, C., y Cáceres, D. (2017). El acaparamiento de tierras como proceso dinámico. Las estrategias de los actores en contextos de estancamiento económico. Población y Sociedad, 24(2), 163-194.

Guber, R. (2012). La etnografía. Método, Campo y Reflexividad. Buenos Aires: Siglo XXI.

Gutiérrez Pérez, A., y Trápaga Delfín, Y. (1986). Capital, Renta de la Tierra y Campesinado. México: Quinto Sol.

Harris, O. (1986). La Unidad Doméstica como Unidad Natural. Nueva Antropología, 7(30), 200- 222.

Hocsman, L., y Preda, G. (2006). Agriculturización y 'Bovinización'. La renovada territorialización capitalista en Córdoba (Argentina). VII Congreso Latino-Americano de Sociología Rural, Ecuador.

INDEC Instituto Nacional de Estadísticas y Censos de la República Argentina, Dirección de Estadísticas e investigaciones (2002). Censo Nacional Agropecuario, datos desagregados provincia de Córdoba.

INDEC Instituto Nacional de Estadísticas y Censos de la República Argentina, Dirección de Estadísticas e investigaciones (2008). Censo Nacional Agropecuario, datos desagregados provincia de Córdoba.

Jelin, E. (Editora) (1991). Family, household and gender relations in Latin America. London: Kegan Paul International.

Marx, K. (2001). El Capital, Libro I, Cap. VI (Ex-inédito). México: Siglo XXI.

Meillassoux, C. (1977). Mujeres, Graneros y Capitales. Siglo XXI: México.

MCC. Movimiento Campesino de Córdoba (2009). El agua en nuestras comunidades. Un Manual práctico para abastecimiento de agua en comunidades campesinas-indigenas, elaborado por el Movimiento Campesino de Santiago del Estero (MOCASE)- Vía Campesina, y el Movimiento Campesino de Córdoba.

Narotzky, S. (2004). Antropología Económica. Nuevas Tendencias. Barcelona: Melusina.

Paz, M. L. (2018). Sobre la multilinearidad de la economía campesina: repertorio de actividades y tensiones. Trabajo y Sociedad, (32), 177-201.

Pegoraro, M., Introcaso, R., y Di Franco, L. (2013). Análisis de los cambios en el uso del suelo en el departamento de cruz del Eje, Córdoba, Argentina. XVI Simpósio Brasileiro de Sensoriamento Remoto, Fos de Iguazú, Brasil. 13- 18 de abril.

Preda, G. (2015). La expansión del capital agrario en el Norte de Córdoba. Transformaciones y disputa por el territorio. Revista de Ciencias Sociales, 28(36), 55-76.

Rausch, G. (2016). Agua, desarrollismo y emergencia de conflicto ambiental: El proyecto hidroeléctrico Paraná Medio en Santa Fe, Argentina (1957-1997). Agua y territorio, (7), 139-151.

Reolín, B. A. (1945). Dique Cruz del Eje. El Ingeniero, (64), 94.

Rockwell, E. (2009). La experiencia etnográfica. Buenos Aires: Paidós.

Romano, M. (2011). Nosotros siempre fuimos campo abierto. Conflictos territoriales, derechos a la tierra y poder judicial en el norte de Córdoba (tesis doctoral). UNC, Facultad de Agronomía, Córdoba.

Roseberry, W. (2007). Hegemonía y el lenguaje de la controversia. En M. Lagos y P. Calla (compiladoras), Antropología del Estado: Cuadernos de Futuro 23, Bolivia: PNDU, pp. 117-139.

Sabattini, A. (1992). Mensajes a la Legislatura cerca del Estado de la Provincia, 1936-1940. Poder Legislativo, Cámara de Diputados, Córdoba: Edición de la Secretaría Técnica Parlamentaria, p. 137.

Sales Martínez, V.; Ortega Reig, M., y Palau-Salvador, G. (2014). Expansión del regadío tradicional y control local en la Real Acequia de Moncada. Ponencia presentada en conferencia: Irrigación, Sociedad y Paisaje, Tributo a T. F. Glick, Universidad Politécnica de Valencia, Valencia, España. Recuperado de: https://www.researchgate.net/publication/276970964_Expansion_del_regadio_tradicional_y_control_lo cal_en_la_Real_Acequia_de_Moncada

Tcach, C. (1991). Sabattinismo y peronismo. Partidos politicos en Córdoba 1943-1955. Buenos Aires: Sudamericana. 
Trabaglia, L. (2007). La realidad operada en las últimas décadas en un espacio que escapa a la economía pampeana: el Noroeste de la Provincia de Córdoba. V Jornadas interdisciplinarias de Estudios Agrarios y Agroindustriales. Facultad de Ciencias Económicas, Universidad de Buenos Aires, 7, 8 y 9 de noviembre.

Vasilachis de Gialdino, I. (2007). La investigación cualitativa. En E. Vasilachis de Gialdino (coordinadora), Estrategias de investigación cualitativa (pp. 23-63). Barcelona: Gedisa.

Veraza, J. (2007). Economía y Politica del Agua. México: Itaca.

Vilar, P. (1990). Presentación. En T. Pérez Piccaso y G. Lemeunier (coord.) Agua y modo de producción (pp. 8-19). Barcelona: Crítica.

Wilk, R., \& McC. Netting, R. (1984). Households: Changing Forms and Functions. En R. Wilk; R. McC. Netting \& E. Arnould, (compiladores.), Households: Comparative and Historical Studies of the Domestic Group (pp.1-28). Los Angeles, Berkeley: University of California Press.

\section{Notas}

1 También efectuamos encuestas a estudiantes secundarios y docentes del Escuela Anexo "Manuel Belgrano" ubicada en la comuna de Guanaco Muerto, lugar donde durante el año 2015 se realizaron reuniones entre vecinos y funcionarios públicos por el conflicto de aprovisionamiento de agua. Entrevistamos, a su vez, al secretario del Ministerio de Agua, Ambiente y Servicios Públicos de la provincia de Córdoba, y al funcionario a cargo de la Dirección General de IrrigaciónAdministración de Recursos Hídricos para Producción de Cruz del Eje.

2 En adelante U.D.

3 El concepto de subsunción del trabajo al capital fue desarrollado por Marx, especialmente en el Capítulo VI -Ex Inéditodel libro I de El Capital (2001). En ese apartado, el autor buscaba extraer conclusiones económico-políticas y sociales del proceso de producción capitalista antes de pasar a analizar el proceso de circulación. La subsunción del trabajo al capital tal como lo describe Marx, en su etapa inicial -subsunción formal-, y en su posterior etapa de consolidación subsunción real- refiere a un proceso identificable tanto en la relación capital/proletariado como en la relación capital/ producción doméstica. Se trata, básicamente, de la subordinación y explotación del proceso de trabajo y de su inclusión dentro del proceso de valorización del capital.

4 La información proviene de los datos desagregados del CNA 2008 para la provincia de Córdoba. Ministerio de Finanzas, Dirección General de Estadísticas y Censos, Gobierno de la Provincia de Córdoba, 2010

5 Los datos son tomados de la página oficial del gobierno de la provincia de Córdoba, Ministerio de Planificación, Inversión y Financiamiento, Secretaría de Planificación. http://hojaprovincial.cba.gov.ar/ (Acceso: Marzo-Abril 2015).

6 De acuerdo lo establece la abogada y Dra. en Estudios Sociales Agrarios Mariana Romano (2011), en la provincia de Córdoba los mecanismos de aplicación de políticas públicas tendientes a sanear títulos de propiedad han resultado históricamente inapropiados y han dejado desamparados a sus legítimos poseedores en todas las regiones del territorio. Entre los factores que han hecho inviable acceder a la justicia a la mayoría de los productores familiares afectados por estos problemas se encuentran los altos costos de mensura y de defensa técnica, los trámites excesivamente lentos, pero fundamentalmente "la propia legislación vigente que no ha dado respuestas a la complejidad de situaciones de la realidad territorial" (p. 53).

7 Estas acciones las están llevando a cabo empresas agropecuarias de larga trayectoria en toda la región del noroeste de la provincia de Córdoba, como así también de nuevos actores, entre los cuales se destacan los pooles de siembra. Así, "la emergencia de estos actores ha sido central en la financiarización de la agricultura, contribuyendo fuertemente al alza del precio de la tierra (Grass y Cáceres, 2017, p. 176). Particularmente, en el departamento Cruz del Eje, se trata de productores extralocales que siembran alfalfa o practican la ganadería de cría, recría, y, en algunos casos, feedlots que cuentan con superficies de entre 500 y 1.000 ha, y su presencia ha ido creciendo en los últimos años de manera exponencial.

8 Es conveniente aclarar que muchos de los grupos domésticos analizados contaban, al momento de nuestra investigación, con ingresos extraprediales fijos provenientes del Estado nacional, sea en forma de pensiones no contributivas o por discapacidad/ancianidad, o planes sociales como la Asignación Universal por Hijo. Si bien no fue objeto de nuestra indagación, constatamos que tales ingresos resultan una "ayuda" que complementa la economía familiar puesto que los ingresos derivados por la actividad predial resultan la base para la sobrevivencia de estos grupos.

9 El MCC es una organización social-territorial con claras reivindicaciones por la tierra -reforma agraria- y la soberanía alimentaria. El MCC integra a nivel nacional el Movimiento Nacional Campesino e Indígena, y a nivel internacional articula con la Coordinadora Latinoamericana de Organizaciones del Campo (CLOC) y con la Vía Campesina. De manera formal se constituye desde fines de los años 90 como Asociación de Productores del Norte de Córdoba 
(APENOC), Unión Campesinos del Oeste Serrano (UCOS), Organización de Campesinos Unidos del Norte de Córdoba (OCUNC), Unión Campesina del Noreste de Córdoba (UCAN), Unión de Campesinos de Traslasierra (UCATRAS), y Organización Zonal Cruz del Eje. (Romano, 2011, pp. 52-53).

10 La Red de Comercio Justo fue creada por el MCC a mediados del año 2002, junto con estudiantes del Movimiento de Base de Agronomía de la Universidad Nacional de Córdoba y estudiantes independientes de otras carreras.

11 Resulta interesante la lectura comparativa con otras zonas de riegos eventuales como es la comunidad de regantes de la Real Acequia de Moncada (RAM) en la huerta de Valencia, donde el espacio regado no ha permanecido totalmente constante, pero sí se establecieron límites prefijados que permitieron mantener una relación entre tierra regable y disponibilidad de recursos adaptada a las necesidades de los usuarios y donde es destacable la importancia de la gestión y toma de decisiones a escala local (Sales Martínez; Ortega Reig y Palau-Salvador, 2014).

12 Vilar (1990) explica que tras la Primera Guerra Mundial hay un impulso por la construcción de obras hidráulicas que generen energía y profundicen la industrialización en los países centrales de Europa. En América Latina, en cambio, la profundización de este proceso es ubicada después de la Segunda Guerra Mundial (en el marco de una Europa necesitada de alimentos y materias primas), a partir de la construcción de megaobras hidroenergéticas que rápidamente tuvo sus consecuencias sociales (Vilar, 1990, p. 17).

13 Gerardo Bergamín es un ingeniero agrónomo que trabaja cuestiones referidas al desarrollo rural y la agricultura familiar en la provincia de Córdoba. Dirige un equipo de investigación y diversos proyectos radicados en la Universidad Nacional de Río Cuarto, Córdoba (Argentina).

14 Cabe recordar que el consorcio de regantes está formado, principalmente, por los empresarios y grandes productores extralocales.

15 Resguardo aquí los nombres reales de los campesinos y campesinas entrevistadas, así como también los nombres de funcionarios o docentes que participaron en la investigación.

16 Los productores dentro de zona de riego pagan un canon similar; la diferencia radica en que a ellos se les otorga por día la misma cantidad de litros de agua que la cantidad de hectáreas productivas que poseen (por caso, 11 hectáreas equivale a recibir 11 litros de agua de riego).

17 Cuando hablamos de reproducción social hacemos referencia a un concepto polisémico que, desde la perspectiva adoptada en este artículo, refiere a las estrategias de sobrevivencia y la reproducción de la vida cotidiana (Jelin, 1984; Bourdieu y Passeron, 1995). Los elementos constitutivos del concepto así entendido son los siguientes: a) El consumo productivo, consumo personal, circulación, distribución y producción, que estarían articulados en un proceso que reproduce los elementos materiales del capital, sus valores y las relaciones sociales existentes entre capital y trabajo; b) La reproducción de la fuerza laboral, que corresponde al mantenimiento cotidiano de los trabajadores y a la distribución de los agentes en posiciones dentro del proceso laboral en el transcurso del tiempo; c) La reproducción biológica, que refiere a la reproducción de las poblaciones humanas en tanto que no existe la fertilidad "natural" y las costumbres sociales influyen en la fertilidad y en la demografía de nuestras poblaciones (Narotsky, 2004, p. 227). 